\title{
ISO/IEC 17025: HISTORY AND INTRODUCTION OF CONCEPTS
}

\author{
Anna Luísa Ribeiro Miguel ${ }^{\mathrm{a}, *,(}$, , Renata Pereira Lopes Moreira $^{\mathrm{a}}$ and André Fernando de Oliveira ${ }^{\mathrm{a}}$ \\ a'Departamento de Química, Universidade Federal de Viçosa, 36570-000 Viçosa - MG, Brasil
}

Recebido em 26/11/2020; aceito em 02/02/2021; publicado na web em 24/02/2021

\begin{abstract}
Quality is an increasingly present concept nowadays, so meeting the customers' needs, who buy and use products and hire services, becomes essential. For laboratories, the concept is applied to the reliability and traceability of the results produced and presents itself not only to meet the customer's needs, but also to allow the signing of agreements in the international trade. The concept of Quality in a laboratory can be carried out from the elaboration of a Quality Management System (QMS). To this end, the normative document ISO/IEC 17025, internationally accepted, has been changing over the years aimed at instructing the elaboration of a management system which proves the technical capacity of testing and calibration laboratories and guides the generation of reliable results. The document is in its third version as a standard, the most current one published in 2017, and it presents requirements to achieve the proposed objective and the quality assurance. In the face of the importance of these concepts and the unquestionable need of laboratories to provide reliable and traceable results, this article presents the norm history and its most recent changes. Its intent is support laboratories whose objective is to implement a QMS according to this normative reference.
\end{abstract}

Keywords: quality management system; quality assurance; laboratory accreditation; traceability; reliable results.

\section{INTRODUCTION}

Testing and calibration laboratories are organizations which provide measurement results and often important decisions are based on these. According to the great responsibility of these laboratories, being able to assure the quality of their service and the reliability of the reported results is important. In order to demonstrate their competence, laboratories through-out the world use the document ISO/IEC 17025. This document proposes a Quality Management System (QMS) that ensure the quality control and metrological traceability. Besides, this document facilitates access to world markets and provides domestic and international socio-economic benefits. ${ }^{1}$

For the sake of making the knowledge about ISO/IEC 17025 increasingly more accessible, this article presents the concept of Quality, this concept applied to laboratories over time, the ISO/IEC 17025 history and the QMS proposed by the new version of this document, published in 2017.

\section{Definition of Quality}

On daily life, the search for products and services that fulfil the customers' expectations is always present. In this way, the presence of Quality is noticeable, and its absence, readily perceived. Quality impacts the success of organizations and the lives of every person in a positive manner. Despite being easily identified, perceptions on Quality do not rely on a clear definition of what quality is. ${ }^{2}$

Several authors have been working on the concept of Quality. For illustrative purposes, Berhe and Gidey ${ }^{3}$ states that the quality of a product is the capacity of such product to meet expectations from both market and customer. Quality has also been defined in the perspective of services. Once that service is not a physical matter and, to a certain extent, is intangible, Quality has, in this context, two approaches to be assessed: technical Quality, which expresses the results delivered to the customer, and functional Quality, which expresses the quality of processes that the customers had to undergo to reach the result. ${ }^{2}$

\footnotetext{
*e-mail: annaluisarmiguel@gmail.com
}

Such study about the concepts of Quality and their development are useful to define what Quality Management more precisely is, establishing it as a field of knowledge with its own line of research. Quality Management is considered a management system which seeks improvement for products and processes by using the organization's self-knowledge. Its main objectives are satisfying the customers and meeting their expectations. ${ }^{4}$

\section{Quality in laboratories}

Just like other organizations, a laboratory must be concerned in satisfying customers and their expectations by delivering both reliable results and a good customer service. Additionally, it must work to assure the quality of its services. ${ }^{4}$

Such concern is shown by Staats, ${ }^{5}$ who declares that, in analytical chemistry, it is not enough just being able to analyse information in order to be of recognized quality. In this case, quality assurance is unavoidable in a high-level, complex market. The author also stresses the importance of a quality system which can assure suitable information management, the latter contributing for reliability and traceability of data.

On the same topic, Christelsohn and Meyer ${ }^{6}$ state how the laboratory's concern for its customers is important and stress that quality management systems are important tools for achieving such goal. The researchers analysed the advantages and disadvantages regarding the prevailing norms and pointed out a robust Quality Management System (QMS) which emphasized more on the customer, the ISO 9001. They also mentioned the norm EN 45001, responsible for proving the technical competence of a laboratory. In such a way, the laboratory's need to assure the quality of its services to its customers is noticeable, regarding both the reliability of its results and the customer service, thus making the origin of a QMS concept very appealing.

According to Olivares, ${ }^{4} \mathrm{QMS}$ is defined as systems put in place seeking to make sure products with the same characteristics and services be delivered in a standardized form, thus ensuring the customers' interests and meeting their expectations. For laboratories, one of the main QMS is the norm ISO/IEC 17025, which was 
developed by the ISO (International Organization for Standardization) and by IEC (International Electrotechnical Commission).

The norm ISO/IEC 17025, whose history shall be detailed further on the text, was adopted by many laboratories worldwide. Since then, conclusions were drawn after the adoption of the QMS proposed by the norm, as seen in the work of Dizadji e Anklam. ${ }^{7}$

Regarding the adoption of the norm ISO/IEC 17025:1999, Dizadji e Anklam ${ }^{7}$ clearly cited the advantages of doing so, such as increased reliability of the laboratory, better efficiency and efficacy, new market opportunities and competitive advantage in comparison to competitors. The authors also stressed the importance of following the proposed QMS to prove the laboratory capable of delivering its services. They also defined competence as the laboratory's capacity to yield reliable results and to meet the customers' needs.

The concern with quality assurance and the analytical laboratories' requirement to have quality control in order to yield reliable results are pointed out by Masson. ${ }^{8}$ The author mentions the existence of texts which foresee the construction of quality systems, i.e. norm ISO/IEC 17025 . Nevertheless, the author also clearly states that the laboratory should know its own routine and must adjust to the requirements of such systems, which can be adopted by laboratories with different characteristics.

Concerns about specific conditions written in the norm can be noticed in works related to the quality assurance of results provided by laboratories, such as the discussion about total error and measurement uncertainty done by Rozet et al..$^{9}$ Another perspective was introduced by Bodnar, Namieśni e Konieczka, ${ }^{10}$ who pointed out the necessity for better attention regarding sampling recommendations, to avoid errors related to the uncertainty estimation of the aforementioned process.

Lastly, in accordance with the trends of normative texts published by international bodies, Wong ${ }^{11}$ highlights the union of the laboratory's risk management to the quality management system. It aims to create action plans, these intended to handle risks and opportunities.

\section{ISO/IEC 17025}

As mentioned, the ISO/IEC 17025 norm proposes the enactment of a QMS for laboratories which wish to show their competence, thus being adopted by many laboratories around the globe. ${ }^{1}$

Currently, the norm is on its third version as an actual norm, and its origin comes from documents issued as Guides in the last decades of the previous century. The document titled "ISO Guide 25: Guidelines for assessing the technical competence of testing laboratories" is considered the first document related to the norm in its current version. This document was issued by ILAC (International Laboratory Accreditation Cooperation) on October 1st $1978 .^{12}$

ILAC is an international cooperation, whose members are accreditation bodies for laboratories according to the current norms, with representatives in more than 70 countries. This cooperation started in October 1977, seeking to develop international cooperations, turning market easier by promoting acceptance of accredited test and calibration results. ${ }^{13}$

The ISO Guide 25 did not address calibration laboratories, only testing laboratories. In the document, there were general guidelines so the laboratories could prove their technical competences. Still, the Guide allowed the evaluation bodies to ask for other requirements other than the ones already stated in the Guide's text. ${ }^{12}$

The requirements stated in the ISO Guide 25 were: organization, staff, protection, testing and measuring equipment, calibration, test methods and procedures, environment, safety, handling of items to be tested, records and test reports. ${ }^{12}$
Such guide was replaced by the "ISO/IEC Guide 25: General requirements for the technical competence of testing laboratories", in December 12th 1982. The document presented itself as both an ISO (International Organization for Standardization) and IEC (International Electrotechnical Commission) document. ${ }^{12}$

The ISO is an independent, non-governmental, international organization, made of members from 162 countries. It was created in 1947 to ease international coordination and to unify industrial standardization. Nowadays it has 784 technical committees and subcommittees responsible for the development of international standards. ${ }^{14}$

The IEC, created on 1906, is a worldwide organization that creates and publishes international standards in the electrotechnical area. When plausible, both organizations unite to assure the construction of international standards, which are complementary to each other due to the collaboration between correlated professionals. ${ }^{15}$

The ISO/IEC Guide 25 still used to address only testing laboratories and mentioned, in the "Scope and field of application" topic, that it could be used by accreditation and certification bodies, governmental and non-governmental bodies related to the technical competence of laboratories. ${ }^{15}$

The requirements stated in the previous document were: organization, quality system, staff, testing and measuring equipment, calibration, test methods and procedures, environment, safety, handling of items to be tested, records and test reports. ${ }^{12}$ It must be noticed that, when comparing it with ISO Guide 25 , the quality system requirement was added.

As mentioned, at the time, international guides only involved testing laboratories until, in 1990, the "ISO/IEC Guide 25: General requirements for the competence of calibration and testing laboratories" was published. ${ }^{12}$

This version of the ISO Guide 25 shows the effort from ISO/ CASCO to publish documents that allow laboratory certification to be made based on internationally established documents. The CASCO (Council Committee on Conformity Assessment) is responsible for the documents' issuance, gained by consensus from the Committee itself supported by the ISO and IEC Councils. The purpose of such efforts is to provide support for national systems, thus easing bilateral agreements. $^{12}$

The requirements stated in this version of the ISO Guide 25 were: organization and management, quality system, audit and critical analysis, staff/personnel, facilities and environment, equipment and reference material, measurement and calibration traceabilities, calibration and test methods, handling of the calibration and test items, records and certificates and reports. ${ }^{12}$ The Guide also emphasized that by meeting these criteria, the laboratories would meet the criteria of the ISO 9000 norm. $^{12}$

The ISO Guide 25 was the last written version of this document as a Guide, even though, according to Van de Leemput, ${ }^{16}$ it had already been written in the norm format by using vocabulary like "shall" and "must" instead of "should" and "may". This document was replaced on 1999 by the norm "ISO/IEC 17025: General requirements for the competence of testing and calibration laboratories".

A revision request sent to ISO, on 1993, made by the European Technical Committee on Conformity Assessment after the Guide's failure to replace the prevailing European document on technical competence and laboratory accreditation. On 1994, CASCO decided in favour to revise the Guide after a meeting with the stakeholders. ${ }^{16}$

In order to successfully revise the Guide, the main principle was that the new document should allow laboratories to display their competence, whether they were interested in accreditation or not. Despite the new principle, only the revised Guide's requirements were used as criteria for accreditation. ${ }^{16}$ 
The revision process took around 6 years, when drafts were written, discussed and voted on. During the process, it was decided that, if IEC approved the document, its prefix would be ISO/IEC. On November 1999, the document got 95\% approval rate, being published on December 15th $1999 .{ }^{16}$

Also during the process, it was agreed that the revised document's relation with ISO 9001 should be clear, with no ambiguity, and its text should cover all aspects of ISO 9001. With this provision, a laboratory which met ISO/IEC 17025 requirements would meet the ISO 9001 requirements too. ${ }^{16}$

It was decided that the new document's requirements would be divided in two categories: management requirements and technical requirements. The ISO/IEC 17025:1999 was divided as follows: 1. Objective; 2. Normative References; 3 . Terms and definitions; 4. Management requirements; 5. Technical requirements; Annex A; Annex B; References.

The requirements of item 4, management requirements, addressed the following topics: organization (4.1); quality system (4.2); document control (4.3); review of requests, tenders and contracts (4.4); subcontracting of tests and calibration (4.5); service and supply purchase (4.6); customers' service (4.7); complaints (4.8); non-compliant tests and/or calibration work control (4.9); corrective action (4.10); preventive action (4.11); record control (4.12); internal audits (4.13); review by management (4.14).

The requirements of item 5 , technical requirements, addressed the following topics: general (5.1); staff (5.2); facility and environmental conditions (5.3); test and calibration methods and method validation (5.4); equipment (5.5); metrological traceability (5.6); sampling (5.7); handling of test and calibration items (5.8); quality assurance of tests and calibration results (5.9); reporting of results (5.10).

According to Van de Leemput, ${ }^{16}$ ISO 9001 norm was also under revision and the publication of its new version was due in 2000 . Nevertheless, the ISO/IEC 17025 was issued in 1999 based on the ISO 9001 norm of 1994. Even though the latter norm would be outdated in a short time, the ISO/IEC 17025 was published in 1999 due to the large demand for it and the illogicality of being based on an unfinished, future norm.

Therefore, on May 2005, the new version of ISO/IEC 17025 was published, and it fit the revision of the ISO 9001 norm, published in 2000. There are no fundamental differences between the 1999 and 2005 version of the norm. Some of the differences are: highlighting of the continuous improvement of the quality management system; more emphasis on establishing effective communication with the customer; use of data to assess the performance of the quality management system and to identify improvement opportunities. ${ }^{17}$

The 2005 version had the following division: 1. Objective; 2. Normative references; 3 . Terms and definitions; 4. Management board requirements; 5. Technical requirements; Annex A; Annex B; References.

The requirements of item 4, management board requirements, addressed the following topics: organization (4.1); management system (4.2); document control (4.3); review of requests, tenders and contracts (4.4); subcontracting of tests and calibrations (4.5); service and supply acquisition (4.6); customer service (4.7); complaints (4.8); non-compliant test and/or calibration work control (4.9); improvement (4.10); corrective action (4.11); preventive action (4.12); record control (4.13); internal audits (4.14); review by management board (4.15).

The requirements of item 5 , technical requirements, addressed the following topics: general (5.1); personnel (5.2); facility and environmental conditions (5.3); test and calibration methods and method validation (5.4); equipment (5.5); metrological traceability (5.6); sampling (5.7); handling of test and calibration items (5.8); quality assurance of test and calibration results (5.9); reporting of results (5.10).

On the 2005 version of the document, it is possible to notice that the management requirements are assigned to the management board instead to the managers. Due to the focusing of the continuous improvement of the QMS, the topic "Improvement" was added to the management requirements (item 4 ).

A new version of the ISO/IEC 17025 was issued on 2017 in order to update and align it to other current norms, including the ISO 9001. To this purpose, the new version included requirements for competency, impartiality, and consistent laboratory operation. ${ }^{18}$

The new document has a different structure compared to the older version, and it is not divided into management requirements and technical requirements. The 2017 version is divided as follows: 1 . Scope; 2 . Normative references; 3 . Terms and definitions; 4 . General requirements; 5 . Structural requirements; 6 . Resource requirements; 7. Process requirements; 8. Management system requirements; Annex A; Annex B; References/bibliography.

The newest version is more process-focused instead of the older procedural focus, decreasing the number of required policies and procedures. The Quality Manual is now optional, letting the laboratory decide to establish it or not. The division between technical management and quality management was replaced by the laboratory general responsibility management. ${ }^{18}$

In General requirements, the norm stablishes specific requirements for impartiality and for confidentiality, stressing their importance, in consideration that they are not restricted to the laboratory policies. This version also emphasizes risk management, pointing out the need for risk identification in many of the norm's requirements. ${ }^{18}$

The development of the document in all its version and publications are displayed on Table 1.

\section{ISO/IEC 17025:2017}

As previously mentioned, the new version of ISO/IEC 17025, published in 2017, was required to update and align the document to current versions of other norms, including ISO 9001. So, in this intent, it is possible to point out some main differences between the previous version (2005) and the updated version (2017).

The 2017 version presents a definition for "Laboratory", in which it is defined as a body that performs at least one of the three activities

Table 1. History of the norm ISO/IEC 17025

\begin{tabular}{ccll}
\hline Version & Year & Type & \\
\hline First & 1978 & Guide & ISO Guide 25: Guidelines for assessing the technical competence of testing laboratories \\
Second & 1982 & Guide & ISO/IEC Guide 25: General requirements for the technical competence of testing laboratories \\
Third & 1990 & Guide & ISO/IEC Guide 25: General requirements for the competence of calibration and testing laboratories \\
Fourth & 1999 & Norm & ISO/IEC 17025: General requirements for the competence of testing and calibration laboratories \\
Fifth & 2005 & Norm & ISO/IEC 17025: General requirements for the competence of testing and calibration laboratories \\
Sixth & 2017 & Norm & ISO/IEC 17025: General requirements for the competence of testing and calibration laboratories \\
\hline
\end{tabular}


that are presented as "laboratory activity": testing, calibration and sampling followed by testing or calibration (3.6). It is noticeable that sampling is presented as a laboratory activity. ${ }^{19,20}$

The concepts of impartiality and independency are differentiated (3.1), and the requirements about impartiality (4.1) and confidentiality (4.2) must be aligned with ISO/CASCO orientation. ${ }^{19,20}$ Furthermore, the risk-based thinking is implemented, in alignment with the ISO 9001 new version (2015). This proposes the monitoring of risks associated with impartiality and laboratories activities. It is suggested classifying the appointed risks according to seriousness and tracking them with the intention of maintaining them under control (8.5). ${ }^{19,20}$

The term "decision rule" is introduced and it states that the laboratory has to define and apply some criteria in order to decide if the obtained result fulfills the requirements, in view to attend the client's demands (7.1.3). . $^{19,20}$

Requirements now focus on the outcome, ensuring quality work and validity of result, which provides more flexibility to laboratories. Besides, the requirements deal with the processes of laboratory activities, looking for a consistent approach on the process and oriented, in the document, by the necessity of documentation of the laboratory's requirements, retention of records and effective communication with people and organizations affected. ${ }^{19,20}$

This new version has put attention in the technology advance, considering electronic management of data and information (7.11). ${ }^{20}$ Lastly, the document was restructured, and the requirements are now organized in different sections: according to the content division of the 2017 norm, the obligatory requirements for laboratories are described in the sections: 4. General requirements; 5 . Structural requirements; 6 . Resource requirements; 7. Process requirements, and 8. Management system requirements.

The requirements are grouped based on their characteristics. It can be visualized on Figure 1 how they correlate to each other to create a QMS, which has the purpose to meet all proposed requirements. Therefore, Figure 1 is a graphic representation of ISO/ IEC 17025:2017, with the objective of making the norm's requirement groups easier to understand.

The requirements which belong to Section 5, Structural requirements, address the aspects that make the laboratory capable of doing its activities, the latter being considered the base of the QMS. On Figure 1, the laboratory structure is represented in a way that it encompasses all requirements left. The next group to be represented is Section 4, General requirements, which addresses impartiality and confidentiality in the development of the laboratories' activities, setting up the risk to impartiality management in a continuous manner. On Figure 1, this section is located with the structural requirements group.

After the definition of the QMS basic parts, the management processes are represented. They guide and encompass all laboratory activities developed by the laboratory. These processes are represented in lilac, are separated in four blocks, and encircle the remaining requirements. These processes must be executed in the same manner for all tests addressed by the QMS, while other requirements might be specific depending on the laboratory activity. Most of these processes are requirements of Section 8, Management requirements, and include some requirements of Section 7, Process requirements.

Inside the representation of the management processes are the processes directly related to the execution of laboratory activities, that may be specific. The Figure 1 represents a laboratory whose activities are restricted to tests only, excluding sampling activities. The processes represented by blue correspond to the Section 6 requirements, Resource requirements, and the processes in yellow correspond to the Section 7, Process requirements. These processes are placed in order to clarify how both resource and process requirements correlate to each other.

In order to compare the 2017 version with the previous one (2005), it can be stated that the management requirements, previously categorised in section 4, are now reorganised within sections 4, 5 and 8 ; and the technical requirements, previously categorised in section 5 , are now reorganised within sections 6 and 7 .

Given all the main changes between the 2005 and 2017 versions mentioned above, it is concluded that the new version of the norm proposes a more efficient management system, reducing the number of mandatory procedures and not requiring a quality manual, but focuses on consistent processes, with personnel able to perform them and maintain objective evidence of activities duly recorded. This new proposition may help laboratories to create and implement a QMS consistent with its own reality, according to the size of the personnel of each laboratory and the activity it develops (calibration or testing in multiple areas, such as environment, forensics, food and others). Also, the risk management is proposed to help laboratories assure the quality of its activities once the risk to laboratory activities and impartiality are now duly monitored and treated.

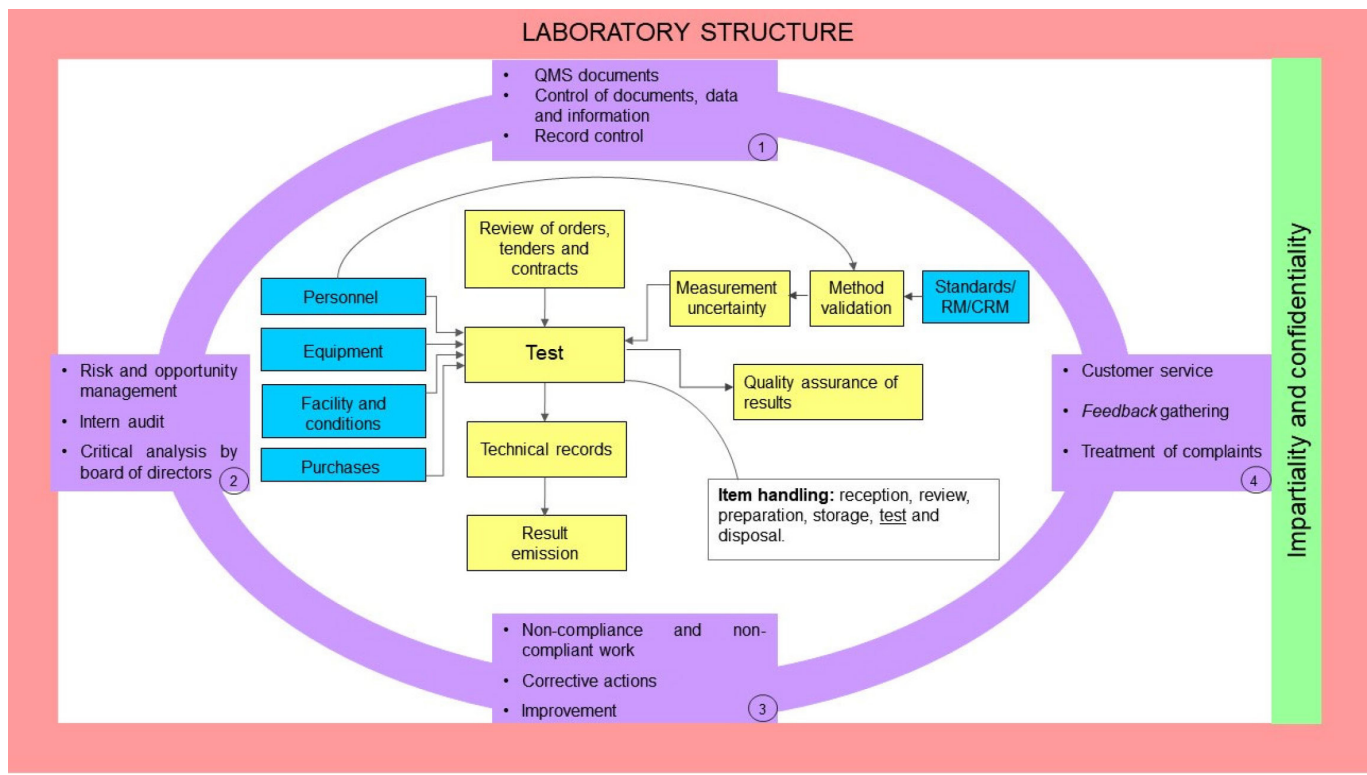

Figure 1. Graphic representation of ISO/IEC 17025:2017 
In addition, this new version highlights the importance of meeting the customer demands through the adoption of a decision rule to report a final result. Focusing on the importance of the measurement provided by the laboratory to the customers' interests, this position reinforces the importance of laboratories to provide reliable and traceable results to support the decision making in different situations.

In this way, ISO/IEC 17025 proposes a QMS through the requirements established and mentioned above to prove the technical competence and ensure the quality of the results produced by the laboratory. The use of this document can be presented as a tool to assist the implementation of the Quality concept in testing and calibration laboratories.

\section{CONCLUSIONS}

Since the service provided by testing and calibration laboratories, the measurement results, is largely used to support decision making with social impact, these laboratories must be aware of tools to ensure quality control, and reliable results and apply them in daily activities. As shown, the QMS proposed for ISO/IEC 17025 contributes to the establishment of a routine based on quality assurance. Therefore, testing and calibration laboratories must be responsible with their activities and its impacts, and put quality management and metrological traceability in place.

\section{ACKNOWLEDGMENTS}

The authors are grateful to the Brazilian Agency for financial support: Coordenação de Aperfeiçoamento de Pessoal de Nível Superior (CAPES), Conselho Nacional de Desenvolvimento Científico e Tecnológico (CNPq) and Fundação de Amparo à Pesquisa do Estado de Minas Gerais (FAPEMIG).

\section{REFERENCES}

1. Squirrell, A.; Accredit. Qual. Assur. 2008, 13, 543.

2. Gomes, P. J. P.; Cadernos BAD. 2004, $2,6$.

3. Berhe, L.; Gidey, T.; Intelligent Information Management 2016, 8, 143.

4. Olivares, I. R. B.; Gestão da Qualidade em Laboratórios, $2^{\text {nd }}$ ed., Editora Átomo: Campinas, 2009.

5. Staats, G.; Fresenius' J. Anal. Chem. 1993, 345, 739.

6. Christelsohn, M.; Meyer, J. C.; Accredit. Qual. Assur. 1997, $2,82$.

7. Dizadji, F.; Anklam, E.; Accredit. Qual. Assur. 2004, 9, 317.

8. Masson, P.; J. Chromatogr. A 2007, 1158, 168.

9. Rozet, E.; Marini, R. D.; Ziemons, E.; Hubert, P.; Dewé, W.; Rudaz, S.; Boulanger, B.; TrAC - Trends Anal. Chem. 2011, 30, 797.

10. Bodnar, M.; Namieśnik, J.; Konieczka, P. TrAC-Trends Anal. Chem. 2013, 51, 117.

11. Wong, S-K.; Accredit. Qual. Assur. 2017, 22, 103.

12. Dos santos, L. L.; Mainier, F. B.; Anais VI Congresso Nacional de Excelência em Gestão, Niterói, Brasil, 2010.

13. https://ilac.org/about-ilac/, accessed in February 2021.

14. https://www.iso.org/about-us.html, accessed in February 2021.

15. https://www.iec.ch/about/?ref=menu, accessed in February 2021.

16. Van de Leemput, P. J. H. A. M.; Accredit. Qual. Assur. 2000, 5, 394.

17. UNIDO; Complying with ISO 17025: A practical guidebook for meeting the requirements of laboratory accreditation schemes based on ISO 17025:2005 or equivalent national standards, United Nations Industrial Development Organization: Vienna, 2009.

18. RMMG; Interpretação e Aplicação da ABNT ISO/IEC 17025:2017, Rede Metrológica de Minas Gerais: Belo Horizonte, 2018.

19. NATA; General Accreditation Guidance - ISO/IEC 17025:2017 Gap analysis, National Association of Testing Authorities: Australia, 2018.

20. UNIDO; Tested \& accepted - Implementing ISO/IEC 17025:2017, United Nations Industrial Development Organization: 2020. 